\title{
Semblanza
}

\section{Semblanza de una compañera: la Dra. María Castellano Arroyo}

\author{
Alberto Gomis Blanco \\ Departamento de Cirugía, Ciencias Médicas y Sociales, Facultad de Medicina y Ciencias de la Salud, \\ Universidad de Alcalá (Alcalá de Henares, Madrid, España); alberto.gomis@uah.es
}

Hace poco más de seis años tuve la fortuna de conocer a la Prof. Dra. D ${ }^{a}$ María Castellano Arroyo. Estaba, entonces, tramitando su incorporación a la Universidad de Alcalá en comisión de servicios. Y lo hacía con una modestia inusual para quien tenía acumulados, ya en esos momentos, tantos méritos científicos. Unos méritos que intentaré resumir en los párrafos que siguen y de los que, por motivo de espacio, una gran parte no quedarán recogidos.

María Castellano nació en Jaén, el 8 de enero de 1948, y cursó la licenciatura en Medicina y Cirugía en la Universidad de Granada. Muy pronto se inclinó por la Medicina Legal, como prueba que el último año, de la carrera, fuera alumna interna de dicha materia. En julio de 1972 completó la licenciatura y en abril de 1976 defendió su Tesis Doctoral en la misma Universidad. La Tesis fue premiada por la Real Academia de Medicina de Granada como la mejor del curso 1976-77.

Becaria del Plan de Formación Investigador y Docente en el período 1973-1977. Dio comienzo a su carrera docente, en la Universidad de Granda, a los pocos meses de completar la licenciatura, siendo sucesivamente: Profesora ayudante de clases prácticas (1 de octubre de 1972), Profesora adjunta interna de Medicina Legal (22 de noviembre de 1976) y Profesora adjunta de Medicina Legal, por oposición (10 de octubre de 1978).

En 1978 aprobó la oposición al Cuerpo Nacional de Médicos Forenses (BOE, 12-08-1978). De los cuarenta aprobados, en aquella convocatoria, tan solo dos mujeres frente a treinta y ocho hombres. Casi de inmediato (en el curso 1978-79) disfrutó de una beca posdoctoral, para formación del personal investigador en el extranjero, que la llevó a Lieja (Bélgica) como Asistente extranjero en el Institut de Médecine Légale de l'Université de Liège. Bajo la dirección del profesor Armand André, trabajó en un proyecto sobre marcadores genético-moleculares y su aplicación a la investigación de la paternidad y a la identificación de indicios biológicos.

En 1980 obtuvo la cátedra de Medicina Legal de la Facultad de Medicina en la Universidad de Zaragoza (BOE, 12 de mayo de 1980). Se daba la circunstancia de que, por vez primera, una mujer accedía a una cátedra en la Facultad de Medicina. Permaneció en la capital maña durante dieciséis años. Fundó y dirigió la Escuela profesional de Medicina del Trabajo de la Universidad de Zaragoza y desempeñó, entre otros cargos, la jefatura del Servicio de Toxicología y Medicina Legal del Hospital Clínico Universitario.

Regresó a la Universidad de Granada en 1996, al ganar la cátedra del al área de conocimiento de Toxicología y Legislación Sanitaria, quedando adscrita al Departamento de Medicina Legal y Psiquiatría (BOE, 5-06-1996), departamento que dirigiría a partir del 2005. Además de su amplísima actividad docente, dirigió la Escuela Profesional de Medicina del Trabajo de la Universidad de Granada (2000) y fue presidenta de la Comisión Nacional de Medicina del Trabajo, dependiente del Ministerio de Sanidad, Política Social e Igualdad (2006) y de la Sociedad Española de Medicina Legal y Forense (2001-2005).

Elegida académica de número de la Real Academia Nacional de Medicina, el día 22 de mayo de 2012 leyó su discurso de ingreso sobre “La construcción de la Medicina Legal y Forense en España: después de ciento setenta años, una tarea inacabada", en el que, agradecida, recordaba a sus maestros: Juan Antonio Gisbert Calabuig, Enrique Villanueva, José Castilla, Luis Concheiro y, el ya mencionado, Armand André. Era el momento es que ya había decidido incorporarse a la 
Universidad de Alcalá y, de ahí, que mucho de los que íbamos a ser sus compañeros fuéramos a escucharla.

La incorporación al claustro alcalaíno tuvo lugar en el curso 2013-14, concretamente al Departamento de Cirugía, Ciencias Médicas y Sociales. Como en aquel momento no podían convocarse plazas de funcionario, por las condiciones restrictivas emanadas del Gobierno de la nación, la Dra. Castellano tuvo que esperar hasta bien entrado el año 2015 para ganar la cátedra del área de "Medicina Legal y Forense" de nuestra Universidad (BOE, 20-11-2015). Se implicó, entonces, no sólo en la formación de los alumnos de medicina, sino también en los de derecho. Y ello, sin abandonar los múltiples compromisos académicos y periciales que tenía contraídos con anterioridad, de modo que con una actividad frenética podía estar en Alcalá, Granada, o cualquier otro punto de la nación, rindiendo su actividad el mismo día.

En una entrevista publicada hace unos meses en Andalucía Médica Magazine (número 126, enero-abril 2018), donde se reconocía como la Dra. María Castellano desde su especialidad había revolucionado muchos aspectos de la sociedad, con la realización de pruebas de maternidad y al enfrentarse al problema de la violencia de género, al ser preguntada por los próximos retos de su disciplina, contestaba: "Desde la Medicina Legal y Forense hemos de seguir aportando los avances científicos para el esclarecimiento de los delitos y que los jueces dispongan de buenas pericias médicas que les permitan devolver a la sociedad buenas sentencias".

Más allá de la extensísima labor docente de la Dra. María Castellano, hay que destacar también sus cualidades investigadoras, pues no puede obviarse el gran número de proyectos de investigación en los que ha participado, la mayoría como investigadora principal, y su actividad pericial. Su calidad científica ha sido reconocida por diferentes Academias, pues además de la ya mencionada Real Academia Nacional de Medicina, en la que ocupa el sillón no ${ }^{19}$, el correspondiente a Medicina Legal, es en la actualidad Vicepresidenta de la Real Academia de Medicina y Cirugía de Andalucía Oriental, en la que ingresó en 2007, y Académica Honoraria de la Academia de Medicina de Zaragoza, de la que fue de número desde 1986 a 1997.

Las distinciones que jalonan su trayectoria son numerosísimas: Cruz distinguida de $1^{\underline{a}}$ clase de la Orden de San Raimundo de Peñafort (Ministerios de Justicia, 1982), Cruz al Mérito Policial con distintivo blanco (Ministerio del Interior, 1990), Colegiada de Honor de los Colegios profesionales de Médicos de Jaén y Granada, Premio a la Trayectoria Profesional otorgado por Unión Profesional, en su primera edición (2017), Medalla de Honor del Consejo General de Colegios Oficiales de Médicos (CGCOM, 2018), Doctora honoris causa por la Universidad de Extremadura (2018) y un largo etcétera.

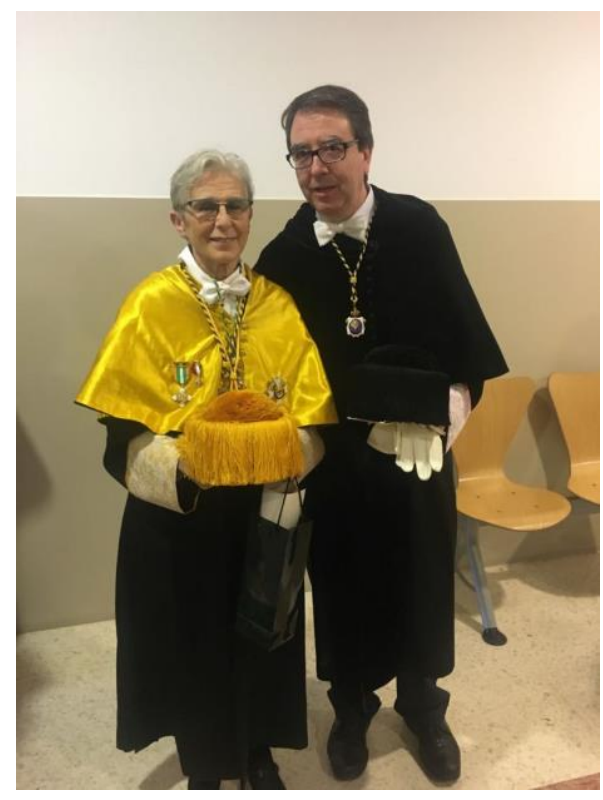

Investidura como Doctora honoris causa de la profesora María Castellano por la Universidad de Extremadura. Con el rector de la UAH Fernando Galván (Badajoz, 7 de febrero de 2018). 
Pero, si no me equivoco, uno de los reconocimientos que más la han agradado le ha llegado recientemente, cuando la Consejería de Conocimiento, Investigación y Universidad de la Junta de Andalucía ha puesto en marcha el programa "María Castellano" que, dirigido a los profesionales del Servicio Andaluz de Salud, permitirá incorporar en un plazo de cinco años a 30 profesores de alrededor de 35 años a la enseñanza universitaria de la Medicina.

El día 26 de junio, de este año 2018, su Departamento de la Universidad de Alcalá, el Departamento de Cirugía, Ciencias Médicas y Sociales, la rindió homenaje por su inminente jubilación, junto a la de los profesores Pedro Carda y Rafael Fernández-Valencia. El entrañable acto, en el que los homenajeados dirigieron sentidas palabras a sus compañeros, estuvo realzado con la presencia del Sr. Rector, profesor José Vicente Saz, y el Sr. Decano de la Facultad de Medicina, profesor Manuel Rodríguez Zapata.

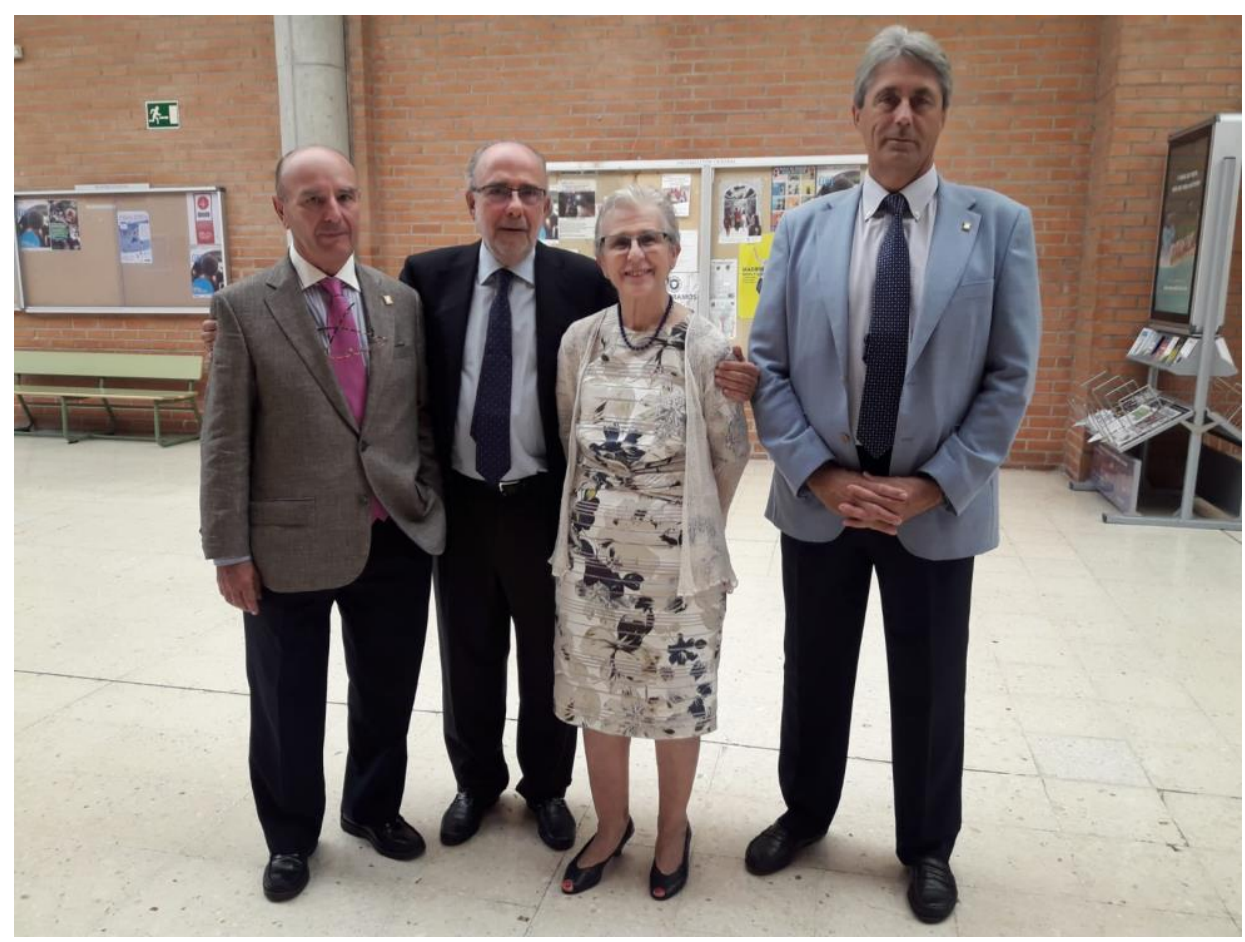

Homenaje del Departamento a los profesores que se jubilaban al final del curso 2017-18. Antes de comenzar el acto, la Dra. María Castellano con los profesores (de izquierda a derecha): Fernando Noguerales (director del Departamento), Manuel Rodríguez Zapata (decano de la Facultad) y José Vicente Saz (rector) (Facultad de Medicina UAH, 26-06-2018, fotografía María Sandín).

Tener de compañera estos años a María ha sido un auténtico privilegio. Siempre dispuesta a ayudar en lo que estuviera de su mano, conversar con ella en su despacho, en un pasillo, en el comedor, en cualquier circunstancia, me ha resultado enriquecedor. Gracias Dra. María Castellano Arroyo. Espero seguir disfrutando de tu sapiencia en la Real Academia de Medicina y espero que, cuando tu múltiple actividad te lo permita, nos visites. Sabes el agrado que ello causa a tus compañeros de la Unidad Docente de Salud Pública, Medicina Legal e Historia de la Ciencia y, estoy seguro, que a toda la Facultad de Medicina de la Universidad de Alcalá. 


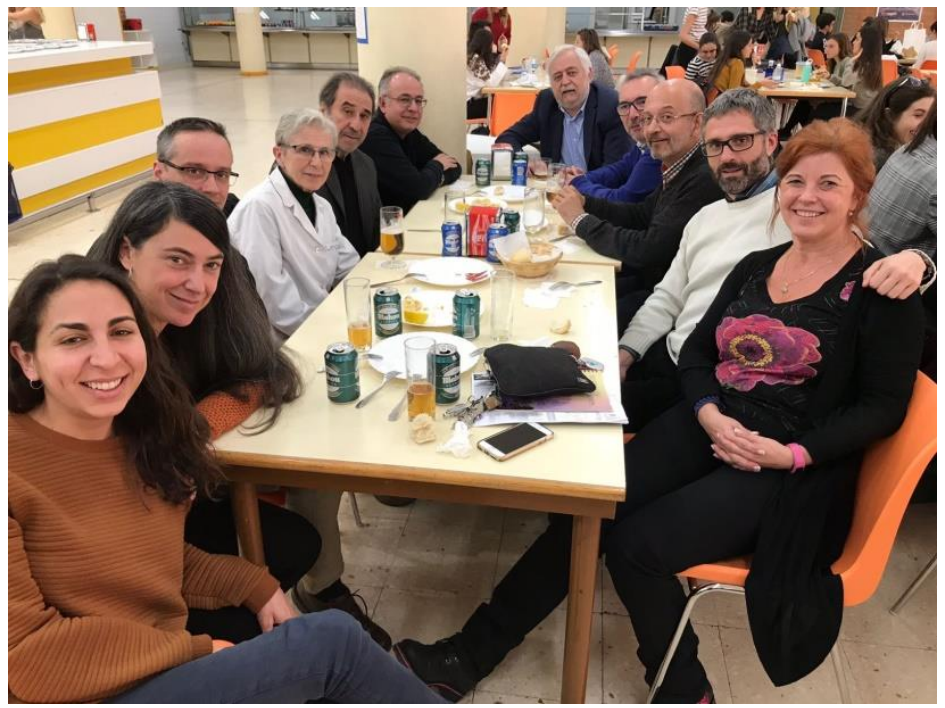

Celebración en la cafetería de la Facultad, probablemente por algún éxito de la Dra. María Castellano, de los miembros de la Unidad Docente de Salud Pública, Medicina Legal e Historia de la Ciencia (Facultad de Medicina UAH, 21-02-2018).

Conflicto de Intereses: el autor declara no tener conflicto de intereses

(C) 2018 por los autores; Esta obra está sujeta a la licencia de Reconocimiento 4.0 Internacional de Creative Commons. Para ver una copia de esta licencia, visite http://creativecommons.org/licenses/by-nc-nd/4.0/. 